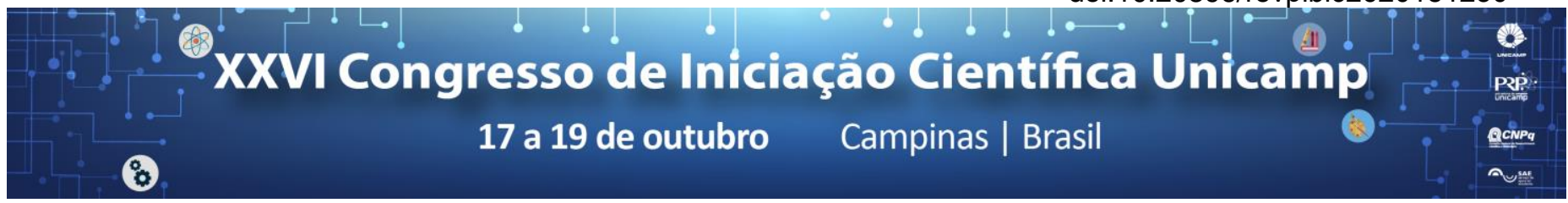

\title{
Comparing two high-intensity ultrasound processes to produce clove bud oil-in-water emulsions
}

\section{Roger Eike Guinosa, Eric Keven Silva, Maria Isabel Landim Neves, Maria Angela Almeida Meireles}

\begin{abstract}
The aim of this work was to compare two high-intensity ultrasound (HIUS) emulsification processes: high power short time (HPST) and low power long time (LPLT), giving the same specific energy of $10 \mathrm{~kJ} / \mathrm{g}$. Clove bud oil-in-water emulsions were obtained from the different HIUS processes. The emulsions were characterized with respect to droplet size distribution, rheological behavior, microestructure, color parameters, kinetic stability and volatile compounds profile by gas chromatography-mass spectrometry (GC-MS).
\end{abstract}

\section{Key words:}

Emerging technology, clove bud oil, volatile compounds profile.

\section{Introduction}

Emulsions are colloidal systems used in the pharmaceutical, cosmetic, and food industries to encapsulate and deliver bioactive compounds. The application of HIUS to emulsification is recognized by several researchers as an efficient means of preparing emulsions ${ }^{1}$. The use of HIUS to form emulsions presents some benefits: HIUS produces more stable emulsions with smaller droplet sizes and narrower size distributions; HIUS requires minimal surfactant quantities; it is easy to operate, control and clean an HIUS apparatus; and HIUS is associated with low production costs ${ }^{2}$. However, HIUS is still considered an emerging technology and, therefore, studies focused on the development of new methodologies and approaches to the application of HIUS technology are necessary so that the industrial sector increasingly develops processes with this technology.

In this way, the aim of this work was to evaluate the impact of different emulsification processes by using HIUS with the same specific energy on the physicochemical properties of clove bud oil emulsion. Two different processes were applied: LPLT (160 W; $26.04 \mathrm{~min}$ ) and HPST (760 W; $5.48 \mathrm{~min}$ ) giving the same specific energy of $10 \mathrm{~kJ} / \mathrm{g}$. The oil-in-water emulsion was prepared using clove (Eugenia caryophyllus) bud oil obtained by supercritical technology and stabilized with gum acacia (instantgum BB, Nexira Comercial Ltda., São Paulo, SP, Brazil).

\section{Results and Discussion}

According to Figure 1, it was possible to compare the effects of the LPLT and HPST processes and see that not only the appearance but also the kinetic stability of the samples were very similar.

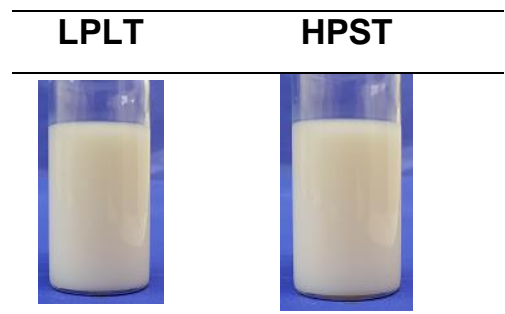

Figure 1. Kinetic stability comparison between LPLT and HPST.
Kinetic stability was evaluated by backscattering profile and the both emulsions presented good stability after 72 hours. Figure 1 demonstrates that difference between color pattern was not visible and also was proved by color parameters $L^{*}, C^{*}$ and $h^{*}$ from the samples.

Table 1 shows that the processes did not modify the emulsions properties in relation to the viscosity and droplet diameter $\left(D_{32}\right)$. Optical microscopy of the emulsions confirmed the similar sizes regardless the HIUS process according to Table 1.

Table 1. Viscosity and droplet diameter.

\begin{tabular}{ccc}
\hline Process & Viscosity $(\mathbf{m P a} . \mathbf{s})$ & $\mathbf{D}_{32}(\boldsymbol{\mu m})$ \\
\hline LPLT & $5.8 \pm 0.1$ & $0.63 \pm 0.04$ \\
HPST & $5.6 \pm 0.1$ & $0.62 \pm 0.01$
\end{tabular}

Chromatographic analysis by GC-MS also showed that HIUS process did not affect the volatile compounds profile present in the respective oil used in the production of the emulsions.

As the analysis exhibited, the way the energy was given did not influence particle size, Newton viscosity and chromatographic characteristics, hence HIUS is a possible technology to be used in food, cosmetic and pharmaceutical industry, adjusting which process is more suitable.

\section{Conclusions}

The results demonstrated that the HIUS is a promising alternative for the production of emulsions with volatile compounds, since regardless of the energy supply way, HPST or LPLT, there were not significant physicochemical changes on the processed systems, furthermore, the processes did not promote any change in the volatile compounds profile.

${ }^{1}$ SILVA, E. K.; GOMES, M. T. M. S.; HUBINGER, M. D.; CUNHA, R. L.; MEIRELES, M. A. A. Ultrasound-assisted formation of annatto seed oil emulsions stabilized by biopolymers. Food Hydrocolloids, v. 47, p. 1-13, 2015.

2 SILVA, E. K.; COSTA, A. L. R.; GOMES, A.; BARGAS, M. A.; CUNHA, R. L.; MEIRELES, M. A. A. Coupling of high-intensity ultrasound and mechanical stirring for producing food emulsions at low-energy densities. Ultrasonics Sonochemistry, v. 47, p. 114-121, 2018. 